occupy about a quarter of the book, what used to be called pteridophytes take another quarter, and the gymnosperms and angiosperms (put with the ferns in the Pteropsida) take more than a quarter. The angiosperms are treated differently from the other groups in that their chapter is a general morphological account of the group and not subdivided systematically as the other groups are.

The book is written in a pleasant style and it is illustrated by numerous clear diagrams. There are not so many photographs or sketches of plants as there are in some of the other textbooks; presumably the student is supposed to see the plants himself. There is a glossary and a short list of references: authors are not referred to directly in the text. The book is up to date and it contains many odd bits of information that are not in similar textbooks. The authors do not express strong opinions on controversial topics; for example, on the nature of the egg of Fucus or whether fertilization ever occurs in the strobilus of Selaginella. A few points are accepted rather uncritically such as the role of apical cells and the mode of operation of a fern annulus; but the book has very few errors of any kind.

Comparing this book with others on the same subject must be done largely on the basis of range of groups described and on attractiveness, for most of the subject matter is well known and the arrangement of the taxa does not matter. There are books that cover fewer of the groups of plants and there are books that also include the fungi. Some are more detailed, others less so. Some people will be attracted by the pictures in some of the others, but, if the student is going to see the plants, there is a lot to be said for using the space for diagrams as Bell and Woodcock have done.

F. A. L. Clowes

\section{MIMETIC PLANTS AND ANIMALS}

\section{Mimicry in Plants and Animals}

By Wolfgang Wickler. Translated from the German by R. D. Martin. (World University Library.) Pp. 255. (Weidenfeld and Nicolson: London, 1968.) 16s. paperback; 30s. hardback.

THIS is an unusually exciting book and should be read by all biologists; in particular the minority who still today cannot accept that mimetic species, and forms of species, have developed by natural selection and not by chance similarity. It can also be read, with pleasure and amazement, by the uninitiated.

In eighteen chapters such diverse examples as mimetic weeds, fish, flowers, mammals, birds and insects are discussed and in addition to Batesian and Müllerian types of mimicry two more are added: "Mertensian Mimicry" with special reference to Professor R. Merten's work on coral snakes (Micrurus sp.), a masterful chapter, and "Peckharnmian Mimicry", as demonstrated by E. G. Peckham's work on aggressive mimicry. The résumé of cuckoos that are brood-parasites (with coloured plates of eggs) and a global perspective of their origin is stimulating. Throughout this book the author has attempted to interconnect and compare the various types of mimicry. It is therefore not surprising that cuckoos are followed by a brief reference to Nicolai's work on widow birds.

An underlying genetic mechanism of mimicry is always difficult to analyse, but Clarke and Sheppard have done this in a series of well-designed experiments on the morphs of the African butterfly, Papilio dardanus, and their work is quoted but with apologies for its complexity. The relationships of the cleaner fish (of which there are so far 42 species in 14 families knowr ) and their aggressive mimics are drawn largely from the work of $\mathbf{H}$. M. Peder. In spite of the extreme degree of accuracy of colourpattern, behaviour, body-size and shape of mimies to models, experienced "customer fish" are able to recognize a difference and therefore, as the author points out, natural selection must still be strictly applied.

This excellent book at the same time offers, gratuitously, odd scraps of other interesting and important information outside its confines. For example, the cuckoopint flower (Arum maculatum) develops a temperature $15^{\circ} \mathrm{C}$ higher than that of its environment, but only for a brief period in a day (Meeuse, and Hocking and Sharplin). The reproduction of the rabbit flea, Spilopsyllus caniculi, is controlled by its host's hormones, enabling young fleas to feed on young rabbits. Adult fleas on rabbits which have aborted reabsorb their eggs (M. Rothschild). North American cuckoos of the sub-family Coccyzinae usually brood their own eggs. Occasionally, however, they oviposit in the nests of other species of bird when they never hatch.

In spite of its distracting interest, there must be criticisms of this book. It is well translated from the original German text by R. D. Martin, but there are many errors. In particular the word "schmetterlinge" whose English equivalent appears, apparently at random, as either "moth" or "butterfly". The bibliography (six pages) is inadequate and there is frequently no reference to the works of the persons quoted in the text (for example, H. M. Peder and E. G. Peckham).

Also I had the greatest difficulty in reading my paperback because, without trauma, the whole book rapidly disintegrated. I recommend an extra fourteen shillings for the hardback. The substance in this book deserves uninterrupted reading.

H. B. D. KettheWell

\section{HYOID APPARATUS IN SNAKES}

The Hyoid and its Associated Muscles in Snakes

By David A. Langebartel. (Illinois Biological Monographs, No. 38.) Pp. 156. (University of Illinois Press: Urbana and London, 1968.) \$4.95; $42 s$.

$\mathrm{As}$, in the nineteenth century, the a priori approach gave way to the empirical, a firm basis for the classification of most groups of vertebrates was established. Snakes, however, missed out on this progress; indeed a prehistoric emotional approach still lingers-men die when bitten by snakes so their most important attribute is the venom apparatus. It has long been recognized that this approach fails to give natural groups of snakes, but no other basis has yet been found. Therefore any work is welcome that reveals diversity within this baffling group and particularly diversity within the "family" Colubridae (two thirds of all known species), an amorphous agglomeration of all the higher snakes that remain after removal of the two main groups of dangerously poisonous forms.

Up to three visceral arches are represented in the hyoid apparatus of lizards, but no snake has more than one arch. The principle of parsimony would suggest that it is the same arch in all, but Dr Langebartel argues, on slender evidence as he recognizes, that it may be the hyoid or the first or second branchial arch. He traces evolutionary trends; as so often in snakes this largely involves simplification, but he finds a fow distinctive features of the musculature that are acquired within the group. The diversity revealed in the lower snakes is most interesting and suggestive. I wish, however, that for the higher snakes Langebartel had made an assessment in the light of his evidence of the attempts at classification that have been made.

The nomenclature seems to have been taken from museum labels without checking; for example, several species are placed in the genus Natrix but the type species remains "Tropidonotus" natrix. If those who make comparative studies do not seek specialist help with systematics and nomenclature, we may afterwards be unsure what species they studied and their own comparisons may be misguided. It is therefore fortunate that Langebartel 